\title{
História, tempo presente e história oral
}

\section{Marieta de Moraes Ferreira}

$\mathrm{N}$

os últimos tempos, grandes transformações marcaram o debate historiográfico, e muito poucos historiadores preservam a crença na capacidade da história de produzir um conhecimento inteiramente objetivo e recuperar a totalidade do passado. A objetividade das fontes escritas com que o historiador trabalha foi definitivamente posta em questão.

A historiografia da Antiguidade clássica, como é sabido, recorreu aos testemunhos diretos na construção de seus relatos. Esse tipo de fonte foi desqualificado na segunda metade do século XIX, mas foi restaurado no século $\mathrm{XX}$ por historiadores que defendiam a validade do estudo do tempo presente. No entanto, a incorporação à disciplina histórica do estudo da história recente e do uso de fontes orais produzidas através da metodologia da história oral não é ponto pacífico: muitas vezes é vista com suspeição e avaliada de forma negativa.

A proposta deste texto é discutir o porquê dessa situação. Para fazê-lo, nada melhor que lançar o olhar sobre a historiografia e observar como a história recente e as fontes orais foram encaradas por diferentes concepçôes da história, e o que levou, em cada caso, à desconfiança e à desqualificação de ambas pelos historiadores.

\section{A emergência do ofício de historiador, a interdição da história recente e do uso de testemunhos diretos}

Por que, no século XIX, a história recente, então chamada de contemporânea, tornou-se um objeto problemático? $\mathrm{O}$ ponto de partida para entender esse processo é a constatação do triunfo de uma determinada definição da história, a partir da institucionalização da própria história como disciplina universitária. Essa definição, fundada sobre uma ruptura entre o passado e presente, atribuía à história a interpretação do passado e sus- 
tentava que só os indivíduos possuidores de uma formação especializada poderiam executar corretamente essa tarefa.

Até 1880, a história, na França, era uma disciplina sem real autonomia, dominada pela literatura e pela filosofia e subordinada ao jogo político das conjunturas. A pesquisa histórica estava sob o controle dos eruditos tradicionais, hostis à República, e não havia um ensino especializado de história. A ausência de formação para a pesquisa histórica explica a grande heterogeneidade de normas para a sua prática. ${ }^{1}$

Gabriel Monod, fundador da Revue Historique (1876), declarava no primeiro número dessa revista que quase todos os seus predecessores eram autodidatas. Dois tipos de pessoas se destacavam como autores dos livros de história. Nas cidades, eram os profissionais liberais, notadamente os advogados, que faziam o papel de historiadores; no mundo rural, eram os quadros da sociedade tradicional, membros da Igreja e da nobreza, que dominavam os estudos históricos. ${ }^{2}$

Foi somente no começo da III República, nos anos 1870, que o lugar da história na sociedade francesa se alterou, e as regras e práticas do métier foram fixadas, num imenso esforço coletivo para romper com o antigo estado de coisas. Preocupadas com a utilização política que os conservadores faziam da história, as novas elites republicanas se empenharam desde sua chegada ao poder em assumir o controle das instâncias de produção da memória coletiva do país.

Foi nesse quadro de afirmação dos historiadores profissionais que se colocou uma condição indispensável para se fazer uma história científica: a visão retrospectiva. O que, exatamente, queria dizer isso?

A afirmação da história como uma disciplina que possuía um método de estudo de textos que lhe era próprio, que tinha uma prática regular de decifração de documentos, implicou a concepção da objetividade como uma tomada de distância em relação aos problemas do presente. Assim, só o recuo no tempo poderia garantir uma distância crítica. Se se acreditava que a competência do historiador se devia ao fato de que somente ele podia interpretar os traços materiais do passado, seu trabalho não podia começar verdadeiramente senão quando não mais existissem testemunhos vivos dos mundos estudados. Para que os traços pudessem ser interpreta- 
dos, era necessário que tivessem sido arquivados. Desde que um evento era produzido ele pertencia à história, mas, para que se tornasse um elemento do conhecimento histórico erudito, era necessário esperar vários anos, para que os traços do passado pudessem ser arquivados e catalogados. ${ }^{3}$

Charles Seignobos, co-autor, junto com Charles Langlois, de Introduction aux études historiques, manual publicado em 1898 que definia as regras de escrita da história, pretendia divulgar os procedimentos e princípios da prática da história científica entre os jovens estudantes e historiadores. Na sua definição, a história tinha como objetivo descrever "por meio de documentos" as sociedades passadas e suas metamorfoses. O documento e sua crítica eram assim essenciais para distinguir a história científica da história literária (praticada pela geração precedente), ou seja, os profissionais dos ensaístas.

Para Seignobos, a prática científica da história deveria ficar restrita ao ensino superior e aos períodos recuados. Na sua concepção, para escrever a história contemporânea, as regras da méthode historique seriam impraticáveis. ${ }^{4}$ Os historiadores de profissão deveriam portanto rejeitar os estudos sobre o mundo contemporâneo, uma vez que nesse campo seria impossível afastar os amadores.

A separação entre passado e presente colocada dessa forma radical e as competências eruditas exigidas para trabalhar com os períodos recuados garantiram praticamente o monopólio do saber histórico aos especialistas. Assim, os historiadores recrutados pelas universidades no século XIX eram especializados na Antiguidade e na Idade Média, períodos que exigiam o domínio de um conjunto de procedimentos eruditos. Com isso pretendia-se impor critérios rígidos que permitissem separar os verdadeiros historiadores dos amadores.

O desprezo dos historiadores universitários pela história recente explica também o porquê da desqualificação dos testemunhos diretos. Esse campo dos estudos históricos acabou se transformando em monopólio dos historiadores amadores. A explicação para essa situação deve-se ao fato de que o período recente não exigia uma farta cultura clássica, nem o controle dos procedimentos eruditos do método histórico. Os que se interessavam pelo contemporâneo na verdade concebiam a pesquisa histórica como um meio de ação política. 
Algumas iniciativas foram feitas no sentido de romper essa barreira e ampliar o espaço temporal dos estudos históricos. Mas, em grande medida, a interdição dos estudos dos períodos recentes foi mantida.

A história contemporânea passou a ter um caráter essencialmente pedagógico, mas sua prática escapava às regras básicas do método histórico-científico. Os historiadores profissionais republicanos diziam que a história contemporânea tratava de eventos muito próximos e não era possível separá-la da política.

Mas como justificar que historiadores profissionais como o próprio Seignobos e Lavisse escrevessem livros sobre o período recente? A resposta fornecida era que se tratava de obras de vulgarização produzidas para o ensino secundário, que tinham caráter pedagógico e deviam formar cidadãos. Seu objetivo não era produzir fatos novos, mas divulgar interpretaçôes novas de fatos já conhecidos. A esse argumento acrescentavam ainda esses autores que a história contemporânea, essencialmente política, se baseava em fontes oficiais. Como essas fontes eram consideradas autênticas, a crítica das fontes, própria do método histórico aplicado ao passado, podia ser dispensável. ${ }^{5}$

Essa maneira de pensar a história em geral, e o contemporâneo em particular, foi alvo de intensos debates na virada do século entre historiadores e sociólogos. ${ }^{6}$ Os sociólogos ligados a Durkheim, em particular Simiand, fizeram pesadas críticas a Seignobos e ao método de pesquisa por ele concebido para garantir a objetividade. Na sua visão, o recuo no tempo não garantia a objetividade da história, pois todo historiador é tributário da sua época.

Os sucessores de Seignobos tentaram mostrar que era possível usar o método histórico para o estudo da época contemporânea. Essas iniciativas dos historiadores profissionais pretendiam retirar a história recente das mãos dos historiadores amadores, mas a desconfiança sobre o tempo recente permaneceu.

Depois de ter desfrutado de amplo prestígio, a concepção de história baseada nos pressupostos da méthode historique formulados pelos historiadores na segunda metade do século XIX entrou em processo de declínio. 
A fundação na França da revista Annales, em 1929, e da École Pratique des Hautes Études, em 1948, iria dar impulso a um profundo movimento de transformação no campo da história. Em nome de uma história total, uma nova geração de historiadores, conhecida como École des Annales, passou a questionar a hegemonia da História Política, imputando-lhe um número infindável de defeitos - era uma história elitista, anedótica, individualista, factual, subjetiva, psicologizante. Em contrapartida, esse grupo defendia uma nova concepção, em que o econômico e o social ocupavam lugar privilegiado.

Essa nova história sustentava que as estruturas duráveis são mais reais e determinantes do que os acidentes de conjuntura. Seus pressupostos eram que os fenômenos inscritos em uma longa duração são mais significativos do que os movimentos de fraca amplitude, e que os comportamentos coletivos têm mais importância sobre o curso da história do que as iniciativas individuais. As realidades do trabalho e da produção, e não mais os regimes políticos e os eventos, deveriam ser objeto da atenção dos historiadores. O fundamental era o estudo das estruturas, em que assume a primazia não mais o que é manifesto, o que se vê, mas o que está por trás do manifesto. O que importa é identificar as relações que, independentemente das percepções e das intenções dos indivíduos, comandam os mecanismos econômicos, organizam as relaçôes sociais, engendram as formas do discurso. Daí a afirmação de uma separação radical entre o objeto do conhecimento histórico propriamente dito e a consciência subjetiva dos atores.

Essa nova maneira de fazer história não alterou contudo a postura anterior no que diz respeito ao período de interesse e às fontes. Da mesma forma que na história dita événementielle, os períodos que receberam maior atenção e se tornaram alvo dos estudos renovadores foram prioritariamente o medieval e o moderno. O século XX recebeu o estigma de objeto de estudo problemático, e a legitimidade de sua abordagem pela história foi constantemente questionada. A impossibilidade de recuo no tempo, aliada à dificuldade de apreciar a importância e a dimensão de longo prazo dos fenômenos, bem como o risco de cair no puro relato jornalístico, foram mais uma vez colocados como empecilhos para a história do século XX. E ainda que Jacques Le Goff tenha apontado a conquista da história 
contemporânea pela nova história como uma tarefa urgente, pouco foi feito nesse sentido. O contemporâneo podia ser matéria das Ciências Sociais em geral, mas não da história. Com isso, a história recente tornou-se uma história sem historiadores.

A imensa transformação que se operou no campo da história a partir da França, e que se difundiu para outros países, tampouco questionou a valorização das fontes escritas. Ao contrário, reafirmou-a. Ao valorizar o estudo das estruturas, dos processos de longa duração, a nova história atribuiu às fontes seriais e às técnicas de quantificação uma importância fundamental. Em contrapartida, ao desvalorizar a análise do papel do indivíduo, das conjunturas, dos aspectos culturais e políticos, também desqualificou o uso dos relatos pessoais, das histórias de vida, das autobiografias. Condenava-se a sua subjetividade, levantavam-se dúvidas sobre as visões distorcidas que apresentavam, enfatizava-se a dificuldade de se obter relatos fidedignos. Alegava-se também que os testemunhos não podiam ser considerados representativos de uma época ou de um grupo, pois a experiência individual expressava uma visão particular que não permitia generalizações. Não é preciso dizer que os historiadores identificados com a tradição dos Annales excluíram a possibilidade de valorização dos testemunhos diretos e das fontes orais.

Ancorada em princípios que sustentavam a necessidade do distanciamento temporal do pesquisador frente ao seu objeto, através do que os historiadores costumam chamar de visão retrospectiva, ou seja, a possibilidade de trabalhar com processos históricos cujo desfecho já se conhece, a história criava limitações para o trabalho com a proximidade temporal, por temer que a objetividade da pesquisa pudesse ser comprometida.

Entretanto, a partir da década de 1980, registraram-se transformaçóes importantes nos diferentes campos da pesquisa histórica. Revalorizou-se a análise qualitativa e resgatou-se a importância das experiências individuais, ou seja, deslocou-se o interesse das estruturas para as redes, dos sistemas de posições para as situaçôes vividas, das normas coletivas para as situaçóes singulares. Paralelamente, ganhou novo impulso a história cultural, ocorreu um renascimento do estudo do político e incorporou-se à história o estudo do contemporâneo. 


\section{A memória em debate}

O aprofundamento das discussões sobre as relaçôes entre passado e presente na história, e o rompimento com a idéia que identificava objeto histórico e passado, definido como algo totalmente morto e incapaz de ser reinterpretado em função do presente, abriram novos caminhos para o estudo da história do século XX. Por sua vez, a expansão dos debates sobre a memória e suas relações com a história veio oferecer chaves para uma nova intelegibilidade do passado. ${ }^{7}$

Segundo Patrick Hutton (1993), o interesse dos historiadores pela memória foi em grande medida inspirado pela historiografia francesa, sobretudo a história das mentalidades coletivas que emergiu na década de 1960. Nesses estudos, que focalizavam principalmente a cultura popular, a vida familiar, os hábitos locais, a religiosidade etc., a questão da memória coletiva já estava implícita, embora não fosse abordada diretamente.

Um dos primeiros autores a chamar a atenção para o tema da memória, segundo Hutton, foi Philippe Ariès, que destacou o papel dos rituais comemorativos com a função de fortalecer os laços familiares no final do século XVIII e início do século XIX. Ariès chamava a atenção também para o papel dos monumentos, das comemorações em torno das figuras políticas ilustres ao longo do século XIX, e de como eles se relacionavam com a emergência dos Estados nacionais. Seguindo a trilha aberta por Ariès, surgiu um novo gênero na historiografia na década de 1980, a história das políticas de comemoração (history of the politics of commemoration). O pioneiro nesse gênero foi Maurice Agulhon, que analisou a imagem da República na França (1789-1879) em sua obra Marianne au combat (1979).

$\mathrm{O}$ trabalho de Agulhon inspirou muitos outros e, assim, alguns anos depois, a questão da memória política, principalmente os temas relacionados com o processo de construção de imagens nas práticas comemorativas, torunou-se uma questão central na produção historiográfica. É nesse contexto que a formulação teórica do sociólogo Maurice Halbwachs ganha destaque passando a integrar o universo teórico dos historiadores. De acordo com Halbwachs, a memória envolve uma relação entre a repetição e a rememoração. Importa porém ressaltar que, ao analisar a repetição das memórias, Halbwachs observou que ela ocorre juntamente com a sua revi- 
são. Outro ponto relevante de sua pesquisa é a afirmação de que a memória coletiva depende do poder social do grupo que a detém. Isto porque, na rememoração, nós não lembramos as imagens do passado como elas aconteceram, e sim de acordo com as forças sociais do presente que estão agindo sobre nós. ${ }^{8}$

Essa contribuição fornece elementos para a elaboração de uma história das comemorações. Ao pesquisar as imagens nas quais os atores históricos representam seu mundo, os historiadores podem identificar as estruturas da imaginação coletiva e o poder do grupo social que as criou.

Tomando como referência as contribuiçóes de Halbwachs, em sua obra Les lieux de mémoire, Pierre Nora propõe uma nova história das políticas de memória e uma história das memórias coletivas da França.

A valorização de uma história das representações, do imaginário social e da compreensão dos usos políticos do passado pelo presente promoveu uma reavaliação das relações entre história e memória e permitiu aos historiadores repensar as relaçôes entre passado e presente e definir para a história do tempo presente o estudo dos usos do passado. Nora aprofunda ainda a distinção entre o relato histórico e o discurso da memória e das recordações. A história busca produzir um conhecimento racional, uma análise crítica através de uma exposição lógica dos acontecimentos e vidas do passado. A memória é também uma construção do passado, mas pautada em emoções e vivências; ela é flexível, e os eventos são lembrados à luz da experiência subseqüente e das necessidades do presente.

Essa perspectiva que explora as relações entre memória e história possibilitou uma abertura para a aceitação do valor dos testemunhos diretos, ao neutralizar as tradicionais críticas e reconhecer que a subjetividade, as distorçóes dos depoimentos e a falta de veracidade a eles imputada podem ser encaradas de uma nova maneira, não como uma desqualificação, mas como uma fonte adicional para a pesquisa. ${ }^{9}$

Se, por um lado, essas transformações no campo da história podem ser avaliadas como positivas, na medida em que permitem uma reflexão histórica menos segura dela mesma, mas mais viva, diagnósticos recentes de especialistas renomados chamam a atenção para a crise epistemológica que acompanha o abalo das antigas certezas dos historiadores. 
O questionamento da crença num passado fixo e determinável, a perda de confiança na quantificação, o abandono de certos objetos históricos ou o questionamento de noções como mentalidade, de categorias como classes sociais, de classificações socioprofissionais e de modelos de interpretação (estruturalista, marxista, demográfico) fizeram a história, no dizer de Roger Chartier, ${ }^{10}$ perder a sua posição de disciplina confederadora das ciências sociais. Por sua vez, o refluxo dos grandes modelos explicativos levou a uma grande dispersão, fazendo com que as principais tradições historiográficas perdessem sua unidade, explodindo em proposições múltiplas e, por vezes, contraditórias.

Todas essas mudanças criaram um espaço novo para o estudo dos períodos recentes, abalando as antigas resistências.

\section{A força das tradições}

A coleta de depoimentos pessoais mediante a utilização de um gravador iniciou-se na década de 1940 com o jornalista Allan Nevins, que desenvolveu um programa de entrevistas voltado para a recuperação de informações acerca da atuação dos grupos dominantes norte-americanos. Esse programa veio a constituir o Columbia Oral History Office, organismo que serviu de modelo para outros centros criados nos anos 50 em bibliotecas e arquivos no Texas, Berkeley e Los Angeles. Esse primeiro ciclo de expansão do que se chamou de história oral privilegiou o estudo das elites e se atribuiu a tarefa de preencher as lacunas do registro escrito através da formação de arquivos com fitas transcritas.

A plena expansão desse processo, que constituiu um verdadeiro boom, teve lugar apenas na segunda metade dos anos 60, prolongando-se ao longo da década de 1970, especialmente nos EUA. As lutas pelos direitos civis, travadas pelas minorias de negros, mulheres, imigrantes etc., seriam agora as principais responsáveis pela afirmação da história oral, que procurava dar voz aos excluídos, recuperar as trajetórias dos grupos dominados, tirar do esquecimento o que a história oficial sufocara durante tanto tempo. A história oral se afirmava, assim, como instrumento de construção de identidade de grupos e de transformação social — uma história oral mi- 
litante. Essa proposta, entretanto, não teve boa acolhida entre a comunidade acadêmica, e menos ainda entre os historiadores.

De toda forma, a idéia da história oral como história dos excluídos expandiu-se para outros países, ganhando adeptos na Inglaterra. A publicação da obra de Paul Thompson, The voice of the past, em 1978, radicalizou a idéia de que a história oral tem por função devolver a história do povo, promover a democratização da história em si mesma. A história oral deveria se afirmar como uma contra-história, operando uma inversão radical nos métodos e objetos consagrados. Deveria ser uma história militante e politicamente engajada.

A penetração da história oral na comunidade dos historiadores, apesar de alguns pontos de afinidade com a nova história, que valorizava o estudo dos excluídos, continuou porém enfrentando fortes resistências. É verdade que nos EUA e na Inglaterra o uso das fontes orais encontrou maior aceitação, propiciando o desenvolvimento de uma linha expressiva de trabalho voltada para o estudo da classe trabalhadora e das minorias. Deve-se assinalar ainda a originalidade da história oral britânica, que não se caracterizou prioritariamente como acadêmica ou universitária.

$\mathrm{Na}$ França, a forte presença da École des Annales e o domínio da abordagem estrutural e quantitativa da história, como já foi dito, revelaram-se fatores inibidores do uso das fontes orais, garantindo o culto do registro escrito.

O que se pode perceber, portanto, é que de início a história oral se desenvolveu em grande medida fora da comunidade dos historiadores. Ainda que guardando as especificidades próprias dos diferentes países com suas distintas tradições historiográficas, o fetichismo do documento escrito, a crença na objetividade das fontes e a concentração do interesse nos períodos mais remotos do tempo destinaram à discussão sobre a história oral ou mesmo apenas sobre o uso das fontes orais — um espaço bastante restrito no contexto dos debates teórico-metodológicos dos historiadores.

No entanto, as transformaçóes recentes ocorridas no campo da história em geral, e na história do século XX, em particular, geraram uma nova discussão sobre o papel das fontes históricas, permitindo que a história oral ocupe um novo espaço nos debates historiográficos atuais. Vejamos que transformações foram essas. 
Em primeiro lugar, a emergência da história do século XX com um novo estatuto, definido por alguns como a história do tempo presente, portanto portadora da singularidade de conviver com testemunhos vivos que sob certo aspecto condicionam o trabalho do historiador, coloca obrigatoriamente em foco os depoimentos orais. Além disso, as próprias tranformaçóes das sociedades modernas e as conseqüentes mudanças no conteúdo dos arquivos, que cada vez mais passam a dispor de registros sonoros, impulsionam a tendência a uma revisão do papel das fontes escritas e orais.

Por outro lado, o retorno do político e a revalorização do papel do sujeito estimulam o estudo dos processos de tomada de decisão. Esse novo objeto de análise também dá maior oportunidade ao uso dos depoimentos orais. Os arquivos escritos dificilmente deixam transparecer os meandros tortuosos dos processos decisórios. Muitas decisões são tomadas através da comunicação oral, das articulações pessoais; o número de problemas resolvidos por telefone ou pessoalmente não pára de crescer. Para suprir essas lacunas documentais, os depoimentos orais revelam-se de grande valia.

A linha historiográfica que explora as relações entre memória e história rompe com uma visão determinista que limita a liberdade dos homens, coloca em evidência a construção dos atores de sua própria identidade e reequaciona as relações entre passado e presente ao reconhecer claramente que o passado é construído segundo as necessidades do presente. Ainda que baseada nas fontes escritas, possibilita uma maior abertura, capaz de neutralizar, em parte e indiretamente, as tradicionais críticas feitas ao uso das fontes orais, consideradas subjetivas e distorcidas.

Ao esquadrinhar os usos políticos do passado recente ou ao propor o estudo das visões de mundo de determinados grupos sociais na construção de respostas para os seus problemas, essas novas linhas de pesquisa também possibilitam que as entrevistas orais sejam vistas como memórias que espelham determinadas representações. Assim, as possíveis distorções dos depoimentos e a falta de veracidade a eles imputada podem ser encaradas de uma nova maneira, não como uma desqualificação, mas como uma fonte adicional para a pesquisa.

Todos esses aspectos, que têm caracterizado as transformações no campo da história a partir da década de 1980, abriram, sem dúvida, um espaço 
para o reconhecimento do uso das fontes orais. No entanto, novos desafios e dificuldades se colocam para que se possa garantir uma maior legitimidade para a história oral no universo dos historiadores.

\section{Historiadores $\mathrm{x}$ history makers}

As drásticas e aceleradas mudanças nas sociedades contemporâneas geram movimentos sociais majoritariamente fragmentados, locais, com objetivos específicos e efêmeros. Nesse contexto, as pessoas tendem a reagrupar-se em torno de identidades primárias (religiosas, étnicas, territoriais, nacionais) como forma de lidar com a diluição de fronteiras e a fragilização das tradições e dos laços interpessoais. ${ }^{11}$

Essa busca desenfreada pela identidade é a fonte principal de significado em um período histórico caracterizado pela ampla desestruturação das organizações, deslegitimação das instituiçõos, enfraquecimento de importantes movimentos sociais e emergência de expressões culturais efêmeras.

A aceleração do tempo e a preocupação com a perda de sentido do passado e com o aumento da capacidade de esquecer têm levado as sociedades contemporâneas a demonstrar grande interesse em recuperar a memória e também a história.

Mas afinal, qual a razão do interesse recente por questões como memória e identidade, manifesto numa busca generalizada de origens familiares, institucionais, setoriais? Talvez essa seja a contrapartida de um processo de globalização que vem transformando visões de mundo e comportamentos, acelerando o tempo da história e produzindo, enfim, um sentimento de insegurança. Voltar às origens significaria reconstituir o trajeto percorrido para definir o rumo da viagem?

Essa tendência é detectada por David Lowenthal quando afirma:

Não mais apenas os aristocratas obcecados pelos ancestrais, nem somente os super-ricos colecionadores de antiguidades, ou apenas antiquários acadêmicos, ou gentry visitantes de museus: agora milhões caçam as suas raízes, protegem cenas amadas, devotam-se a pequenas relíquias do passado. Essa busca pela tradição reflete os traumas das perdas e mudanças, bem como os medos diante de um futuro assustador. ${ }^{12}$ 
O diagnóstico de John Gillis ${ }^{13}$ é de que a memória tornou-se um grande negócio e com isso a comemoração em si passou a ter mais importância do que aquilo que está sendo lembrado. A memória adquiriu, assim como quase tudo no mundo contemporêneo, um atributo de mercadoria. As exposiçóes nos museus, assim como os eventos comemorativos, estão cada vez mais parecidas com espetáculos, afirma Gillis. Entre as múltiplas memórias em circulação, só aquelas que possam referir-se ao indivíduo, de modo quase particular, é que passaram a ser alvo de investidas, de celebrações. A memória invade o cotidiano, mas na maioria das vezes apenas como mais um produto para satisfazer parcialmente uma demanda por identidade, e torna-se assim uma "memória domesticada".

Esse interesse pelo passado tem se manifestado de forma variada e promovido uma confusão entre história e memória e entre o que é ser historiador e history maker. Essa denominação é atribuída aos autores que escrevem sobre o passado sem fazer uso das regras estabelecidas pela comunidade acadêmica, ou que recolhem depoimentos orais carregando a crença em que o relato individual expressa em si mesmo a história. Enfim, generaliza-se uma confusão entre história-objeto e história-conhecimento, entre história vivida e história como uma operação intelectual. Nos últimos tempos tem sido crescente a demanda do grande público pela história vivida e a valorização das obras dos history makers. Essa produção tem sido vista como mais atraente por apresentar uma narrativa de leitura mais agradável e de mais fácil compreensão. Estabelece-se assim uma competição entre duas formas de acesso ao passado e reatualiza-se a disputa entre amadores e profissionais. A história oral, um instrumento privilegiado para recuperar memórias e resgatar experiências de histórias vividas, tem sido amplamente utilizada por esses setores e alçada à condição de uma disciplina. Nesse caso a coleta de depoimentos e sua publicação transformam-se em um fim e si mesmo e não devem ser submetidos à análise crítica da investigação histórica.

\section{História oral: um laboratório de reflexão metodológica}

As constantes críticas dos historiadores tradicionais à história oral estimulam aqueles que a praticam a promover uma permanente reflexão e 
avaliação de seus procedimentos de pesquisa. Esse esforço de resposta às críticas recebidas tem resultado num saldo positivo que não deve ser minimizado. Sem deixar de reconhecer as dificuldades da história oral, podese detectar no método um potencial de pesquisa extremamente rico que não deve nos impedir de tirar o proveito devido de seu uso.

Uma avaliação mais detida do campo do que tem sido chamado de história oral nos permite detectar duas linhas de trabalho que, embora não excludentes e entrecruzadas em muitos casos, revelam abordagens distintas.

A primeira delas utiliza a denominação história oral e trabalha prioritariamente com os depoimentos orais como instrumentos para preencher as lacunas deixadas pelas fontes escritas. Essa abordagem tem-se voltado tanto para os estudos das elites, das políticas públicas implementadas pelo Estado, como para a recuperação da trajetória dos grupos excluídos, cujas fontes são especialmente precárias. No primeiro caso, o estudo da administração pública, das diretorias de empresa e, especialmente, o acompanhamento do processo de tomada de decisões em diferentes espaços e grupos são os temas dominantes. Na recuperação da história dos excluídos, os depoimentos orais podem servir não apenas a objetivos acadêmicos, como também constituir-se em instrumentos de construção de identidade e de transformação social. Ainda que nessa segunda linha se introduzam conceitos de memória coletiva, não se evidencia uma discussão mais aprofundada sobre as implicações do uso da noção de memória. Em muitos casos a noção de memória é apresentada como algo estável e congelado no passado a ser resgatado pelo pesquisador.

O ponto central que unifica as preocupaçóes daqueles que se dedicam ao estudo das elites e dos que se voltam para o estudo dos excluídos é garantir o máximo de veracidade e de objetividade aos depoimentos orais produzidos. Os instrumentos para se atingir tais objetivos seriam a formulação, no caso dos estudos acadêmicos, de roteiros de entrevistas consistentes, de maneira a controlar o depoimento, bem como o trabalho com outras fontes, de forma a reunir elementos para realizar a contraprova e excluir as distorções. Com base nesses procedimentos, erigem-se argumentos em defesa da história oral como capaz de apresentar relatos que, se não eliminam a subjetividade, possuem instrumentos para controlá-la. 
Uma segunda abordagem no campo da história oral é aquela que privilegia o estudo das representações e atribui um papel central às relações entre memória e história, buscando realizar uma discussão mais refinada dos usos políticos do passado. Nessa vertente a subjetividade e as deformações do depoimento oral não são vistas como elementos negativos para o uso da história oral. Conseqüentemente, a elaboração dos roteiros e a realização das entrevistas não estão essencialmente voltadas para a checagem das informações e para a apresentação de elementos que possam se constituir em contraprova, de maneira a confirmar ou contestar os depoimentos obtidos. As distorções da memória podem se revelar mais um recurso do que um problema, já que a veracidade dos depoimentos não é a preocupação central.

Essa última abordagem, assim como a primeira, tem sido adotada para o estudo das elites políticas, quando a intenção principal é compreender o seu imaginário político, e também para o estudo das representaçôes das camadas populares. Nesse caso, todavia, a preocupação dominante tem sido acadêmica, ficando o objetivo de mobilização política bastante secundarizado.

As transformações que têm marcado o campo da história, abrindo espaço para o estudo do presente, do político, da cultura, e reincorporando o papel do indivíduo no processo social, vêm portanto estimulando o uso das fontes orais e restringindo as desconfianças quanto à utilização da história oral. Entretanto, apesar dessas transformações, o debate a respeito da legitimidade da história oral não é assunto resolvido. São constantes as avaliações de historiadores de diferentes países ou que trabalham com diferentes abordagens desqualificando esse método de pesquisa. As resistências vão da rejeição completa, a partir da visão de que o depoimento oral apenas relata intrigas, ao questionamento da expressão "história oral" em favor de "fontes orais".

A principal crítica à expressão "história oral" liga-se ao fato de que nas sociedades modernas não existe um discurso oral puro, e à perspectiva de que um depoimento oral só ganha sua plena significação em confronto com o documento escrito. Além disso, a "história oral" traria embutida a intenção de se constituir em disciplina capaz de uma interpretação científica, 
escamoteando-se assim sua finalidade de produzir fontes que serão objeto de análises e interpretações. Finalmente, critica-se a noção de que a história oral seria uma outra história, uma história alternativa, mais comprometida com a militância política do que com o rigor dos métodos acadêmicos. $\mathrm{Na}$ visão desses críticos, a história oral, tanto dos vencidos como dos vencedores, estaria marcada por deformações ideológicas.

Diferentemente, o uso da expressão "fontes orais" parece encontrar uma aceitação maior. A denominação é ampla e pode ser aplicada a qualquer depoimento oral, produzido por qualquer indivíduo e em qualquer circunstância, sem nenhuma preparação prévia. Há aí uma diferença em relação à história oral, que pressupõe a produção de uma fonte oral específica resultante de um processo de elaboração e pesquisa por parte de um especialista. O emprego generalizado da expressão "fonte oral" conduziria à equiparação de uma fonte produzida pelo historiador com qualquer outra fonte oral, revelando mais uma vez uma desvalorização do método da história oral.

Uma alternativa apresentada por Danièle Voldman para enfrentar as ambigüidades e problemas metodológicos envolvidos na uso da expressão "história oral" é buscar uma terminologia mais adequada a partir da distinção entre "documentação sonora" e "documentação oral". ${ }^{14}$ A primeira incluiria informaçóes registradas através do som em sentido amplo, enquanto a segunda seria o produto da coleta de testemunhos orais, registrados para fins documentais. A mesma autora propõe uma distinção suplementar entre "documentação oral" e "fonte oral", esta última definida como o material recolhido por um pesquisador para as necessidades de sua pesquisa, em função de suas hipóteses particulares.

À parte os problemas de terminologia, outro aspecto negativo do uso das fontes orais apontado pelos historiadores é a dificuldade de controle da comunidade acadêmica sobre as fontes produzidas a partir de entrevistas, pelo fato de estas permanecerem nas mãos de pesquisadores individuais, não sendo facultada sua consulta aos demais interessados. Para contornar essa dificuldade, muitos arquivos e bibliotecas têm criado acervos de depoimentos orais produzidos por seus pesquisadores, mas também abertos para o recebimento e arquivamento de conjuntos de depoimentos produzi- 
dos por pesquisadores externos, como é o caso do Arquivo da Cidade de Barcelona.

Ainda que objeto de poucos estudos metodológicos mais consistentes, a história oral, não como uma disciplina, mas como um método de pesquisa que produz uma fonte especial, tem-se revelado um instrumento importante no sentido de possibilitar uma melhor compreensão da construção das estratégias de ação e das representações de grupos ou indivíduos nas diferentes sociedades.

\section{Conclusão}

A incorporação, hoje, do tempo presente e dos testemunhos diretos ao campo da pesquisa histórica recoloca alguns problemas do começo do século XX. Novamente os historiadores confrontam-se com a competição dos amadores e com o crescimento do interesse pela história política e pedagógica. Os desafios e dilemas que Seignobos enfrentou na virada do século XIX, ao querer preservar a escrita da história para os especialistas que dominavam a méthode historique, ou seja, as regras do métier, e ao mesmo tempo atender às demandas políticas que sua militância republicana e laica exigiam, e assim produzir manuais de vulgarização para o grande público e para a escola secundária, recolocam-se hoje com toda força para os historiadores. ${ }^{15}$

Como fazer valer as regras para a escrita da história científica das teses e monografias eruditas e passá-las ao manual de ensino superior e depois às sínteses para o grande público? A prática científica da história só é possível no ensino superior? Como transformar as novas aquisições inovadoras produzidas pela academia para estendê-las ao grande público? Como fazer uma história seguindo as regras científicas e ao mesmo tempo produzir manuais, filmes, CDs, exposições etc. necessários à formação dos cidadãos das sociedades modernas? São estas as perguntas que hoje estamos sendo convidados a responder. 


\section{Notas}

${ }^{1}$ Noiriel, Gérard. Naissance du métier d'historien. Genèses, Paris, n. 1, p. 58-87, sept. 1990.

${ }^{2}$ Carbonell, Charles Oliver. La naissance de la Revue Historique: une revue de combat (1876-1885). Revue Historique, n. 518, p. 337-351, avr.-juin. 1976.

${ }^{3}$ Noiriel, Gérard. Qu'est-ce que l'histoire contemporaine? Paris: Hachette, 1998.

${ }^{4}$ Prost, Antoine. Douze leçons sur histoire. Paris: s. ed., 1994.

${ }^{5}$ Idem.

${ }^{6}$ Reberioux, Madeleine. Preface in Langlois C. et Seignobos, Charles. Introduction aux études historiques. Paris: Éditions Kimé, 1992.

${ }^{7}$ Rousso, Henry. La mémoire n'est plus ce qu'elle était. In Institut d'Histoire du Temps Présent. Ecrire l'histoire du temps présent. Paris: CNRS Editions, 1993.

${ }^{8}$ Hutton, Patrick. History as an art of memory. University of Vermont. University Press of New England, 1993.

${ }^{9}$ Pollak, Michael. L’historien et le sociologue: le tournant épistémologique des années 1960 aux années 1980. In Institut d'Histoire du Temps Présent. Ecrire l'histoire du temps présent. Paris: CNRS Editions, 1993.

${ }^{10}$ Chartier, Roger. Le regard d'un historien moderniste. In Institut d'Histoire du Temps Présent. Ecrire l'histoire du temps présent. Paris: CNRS Editions, 1993.

${ }^{11}$ Castells, Manuel. A sociedade em rede. São Paulo: Paz e Terra, 1999.

${ }^{12}$ Apud Kammen, Michael.Carls Becker redivivus or, is everyone really a historian? History and Theory, v. 39, n. 2, 2000, p. 233.

${ }^{13}$ Gillis, John. Comemorations: the politics of national identity. Princeton: Princeton University Press, 1994.

${ }^{14}$ Voldman, Danièle. Définitions et usages. Les Cahiers de I'IHTP, n. 21, p.33-53, nov. 1992.

${ }^{15}$ Charle, Christophe. Paris fin de siècle: culture et politique. Paris: Seuil, 1998.

\section{Resumo}

Partindo da interdição da história recente e do uso de testemunhos diretos no século $X I X$, este artigo busca discutir a relação entre passado e presente na história e os novos caminhos para o estudo da história do século XX. Estabelecendo a diferença entre história e memória (e entre historiador e history maker), este trabalho trata dos problemas teóricos e metodológicos da história oral hoje. 


\section{Abstract}

Starting from the interdiction of the recent history and the use of direct testemonies in the XIXth century, this article seeks to discuss the relationship between past and present in history and the new ways of history studies in the XXth century. Establishing the difference between history and memory (and between the historian and the history maker), this work approches the theoretical and methodological problems of oral history today. 